\title{
VaR BASED RISK MANAGEMENT
}

Mária Bohdalová, Michal Greguš, Comenius University in Bratislava, maria.bohdalova@fm.uniba.sk, michal.gregus@fm.uniba.sk

In this paper we discuss the Value-at-Risk concept and we analyse the market risk by using EWMA approach. EWMA (exponentially weighted moving average) forecasting technique is a popular measure of various risks in financial risk management. We will compare standard EWMA, robust EWMA and skewed EWMA forecast of VaR. JP Morgan standard EWMA is derived from Gaussian distribution. Robust EWMA is based on Laplace distribution and skewed EWMA is a new approach derived from an asymmetric Laplace distribution. Asymmetric Laplace distribution takes into account both skewness and heavy tails in return distribution and the time varying nature of them in practice. Skewed EWMA VaR is a generalization of the standard EWMA method. Using these approaches we will analyse selected financial series (three European market indexes and one exchange rate). We have found and confirmed that skewed EWMA forecasting of VaR outperforms the standard EWMA method.

JEL Classification Numbers: C15, G17, G32, G11, DOI: 10.12955/cbup.2013.11

Keywords: EWMA VaR, robust, skewed EWMA VaR, Value-at-Risk

\section{Introduction}

The global financial system is under the influence of the crisis that began in 2007-2008. Due to the interdependency of national economies its effects are felt all over the world. Many banks have not been able to pay market losses: they did not create enough capital to ensure coverage of unexpected adverse effects. The lack was of such a scale that many institutions had to be rescued by the government at the expense of the taxpayer funds. The current framework contained in the Basel II Capital Accord (Basel Comitee, 1996) introduced Value-at-Risk (VaR), one of the most widely applied risk measures nowadays, which is used to quantify large losses related to the probabilities of their occurrence.

\section{Literature review}

VaR concept was introduced at the end of the 1980s, and since then, it has become increasingly popular measure of the degree of various risks in financial risk management, especially as measurement for the market risk (De Schepper \& Heijnen, 2010). To be precise, VaR is the maximum expected loss over a given horizon period at a given level of VaR. VaR methodology is relatively recent. The topic has been described in monographs (Duffie, 1997; Dowd, 2002; Jorion, 2007, 2009; Dempster, 2002; Longerstaey \& Spencer, 1996) and several topics have been studied in the papers (Duffie \& Pan, 1997; Fong \& Vasicek, 1997; Zmeškal, 2005), etc. J.P.Morgan has established a market standard through Risk Metrics system for example in: Morgan (1996), Longerstaey \& Spencer (1996), Linsmeier \& Pearson (2000), etc. 
Due to facts present in financial time series a key problem in financial research, and particularly in the field of risk management, is the choice of models so as to avoid systematic biases in the measurement of risk. JP Morgan`s Risk Metrics system invented EWMA (exponentially weighted moving average) VaR forecasting technique. The EWMA estimator is based on the maximum likelihood estimator of the variance of the normal distribution, and is thus optimal when returns are conditionally normal. However, if there is sample evidence that the conditional distribution of short horizon financial asset returns is leptokurtic, then the EWMA estimator will generally be inefficient in the sense that it will attach too much weight to extreme returns (Guermat \& Harris, 2001). Guermat and Harris (2001) introduce robust EWMA VaR estimator that is based on the maximum likelihood estimator of the standard deviation of the Laplace distribution, and it is a function of an exponentially weighted moving average of the absolute value of past returns, rather than their squares. Later Lu et al. (2010) derived skewed-EWMA VaR estimator that has taken into account both skewness and heavy tails in return distribution and also their time - varying nature in practice. In this paper we compare standard EWMA, robust and skewed EWMA VaR estimators.

The outline of the paper is as follows. The following section introduces data and methodology of the VaR and describes standard and skewed EWMA VaR estimator. Robust EWMA estimator is introduced as a special case of the skewed EWMA estimator. Section Results and Discussion presents our empirical results. Section Conclusion offers some concluding remarks.

\section{Data and methodology}

We generate out-of-sample VaR forecast for three European market indexes: CAC 40, DAX, FTSE and exchange rate GBP/EUR obtained from Bloomberg for period of January 3, 2000 to January 2, 2013. All the estimation process is carried out in Wolfram Mathematica v. 9. We compute daily log returns of the closing price for all return series denominated in euro. A sample plot is enough to observe volatility clustering for all return series (Figure 1). Table 1 provides summary statistics of all daily log return series and gives for example the mean, standard deviation, skewness, kurtosis, JarqueBera test of normality. In all cases, the null hypothesis of normality is rejected at any level of significance, and there is evidence of significant excess kurtosis of the return series. This indicates that the distributions of these return series are non-Gaussian (Figure 1).

\section{Value at Risk}

We compute out-of sample ten day VaR forecasts for all return series. Measuring the overall risk can be done in two principal ways: a statistical based approach called Value at Risk (VaR) or an approach based primarily on economic insight rather than statistics. In this paper we will discuss the potential uses of the VaR methodology.

Value at Risk (VaR) is a statistical risk measure that expresses the maximum loss in the value of exposures due to adverse market movements that a company is reasonably confident, will not be exceeded if its positions are maintained static during a certain period of time $t$ (Rossignolo et al., 2012).

$$
\operatorname{VaR}(\alpha)=\inf \{l \in R: P(L>l) \leq(1-\alpha)\}=\inf \left\{l \in R: F_{L}(l) \geq \alpha\right\},
$$

where $F_{L}$ denotes the loss distribution function. 
CBU INTERNATIONAL CONFERENCE ON INTEGRATION AND INNOVATION IN SCIENCE AND EDUCATION

Table 1: Descriptive statistics based on the daily log return series, from 3. 1. 2000 to 2. 1. 2013

\begin{tabular}{|l|l|l|l|l|}
\hline Descriptive statistics & CAC 40 & DAX & GBP/EUR & FTSE \\
\hline Mean & -0.0001 & 0.0000 & -0.0001 & -0.0001 \\
\hline Mean Ann. & -0.0345 & 0.0106 & -0.0191 & -0.0265 \\
\hline Median & 0.0001 & 0.0006 & 0.0001 & 0.00032 \\
\hline Max & 0.1059 & 0.1080 & 0.0272 & 0.2075 \\
\hline Min & -0.0947 & -0.0743 & -0.0314 & -0.2999 \\
\hline Stand. Dev. & 0.0156 & 0.0161 & 0.0050 & 0.01519 \\
\hline Stand. Dev. Ann & 0.2474 & 0.2549 & 0.0795 & 0.240242 \\
\hline Skewness & 0.0357 & 0.0340 & -0.1620 & -1.58297 \\
\hline Kurtosis & 7.5615 & 6.9953 & 5.8129 & 61.96249 \\
\hline Jarque-Bera $t$ stat & 2912.6275 & 2234.7141 & 1122.5088 & 487572.9 \\
\hline Jarque-Bera $p$ value & 0.0000 & 0.0000 & 0.0000 & 0.0000 \\
\hline Sample size & 3341 & 3341 & 3341 & 3341 \\
\hline
\end{tabular}

Source: Calculated by the authors with Wolfram Mathematica software using data from Bloomberg

VaR could be characterised as

$$
\operatorname{VaR}(\alpha)_{t+1}=\sigma_{t+1} F^{-1}(\alpha)
$$

where $\sigma_{t+1}$ is the volatility of the loss distribution function $F$ (measured by the standard deviation) and $F^{-1}(\alpha)$ is the inverse of the loss distribution function, i.e., $\alpha$-quantile of $F$.

$\mathrm{VaR}$ is a good tool that risk managers should be aware of in order to act on hedging their risky positions. VaR is also being accepted as a standard measurement to specify banks regulatory capital by BIS. Therefore, many parties in the financial markets such as institutions, wealthy investors, authorities, auditors, and rating agencies are able to monitor market risk regularly and accept different confidence level for their VaR calculations (Culp, Mensink \& Neves, 1999). When comparing two different portfolios' VaR number, the time horizon must be the same. To compare one day and ten days VaR numbers is not meaningful (Penza \& Bansal, 2001; cited in Korkmaz \& Aydin 2002). In financial market, the typical time horizon is somewhere between 1 day to 1 month. Time horizon is chosen based on the liquidity capability of financial assets or expectations of the investments. Confidence level is also crucial to measure the VaR number. Typically in the financial markets, VaR number is calculated for confidence level between 95\%-99\%. Confidence level is chosen based on the objectives such as Basel Committee requests $99 \%$ confidence level for banks regulatory capital. For insiders, confidence level could be lower.

\section{Standard EWMA based VaR modelling}

Risk Metrics (Morgan, 1996) measures the volatility by using EWMA model that gives the heaviest weight on the last data. Exponentially weighted model gives immediate reaction to the market crashes or huge changes. Therefore, this model reflects these rapid changes. If we give the same weight to all data, it is difficult to capture extraordinary events and effects. 
Figure 1: Histogram and log returns of the European stock indices CAC 40, DAX and FTSE and for exchange rates GBP/EUR from January 3, 2000 to January 2, 2013 (denominated in EUR)
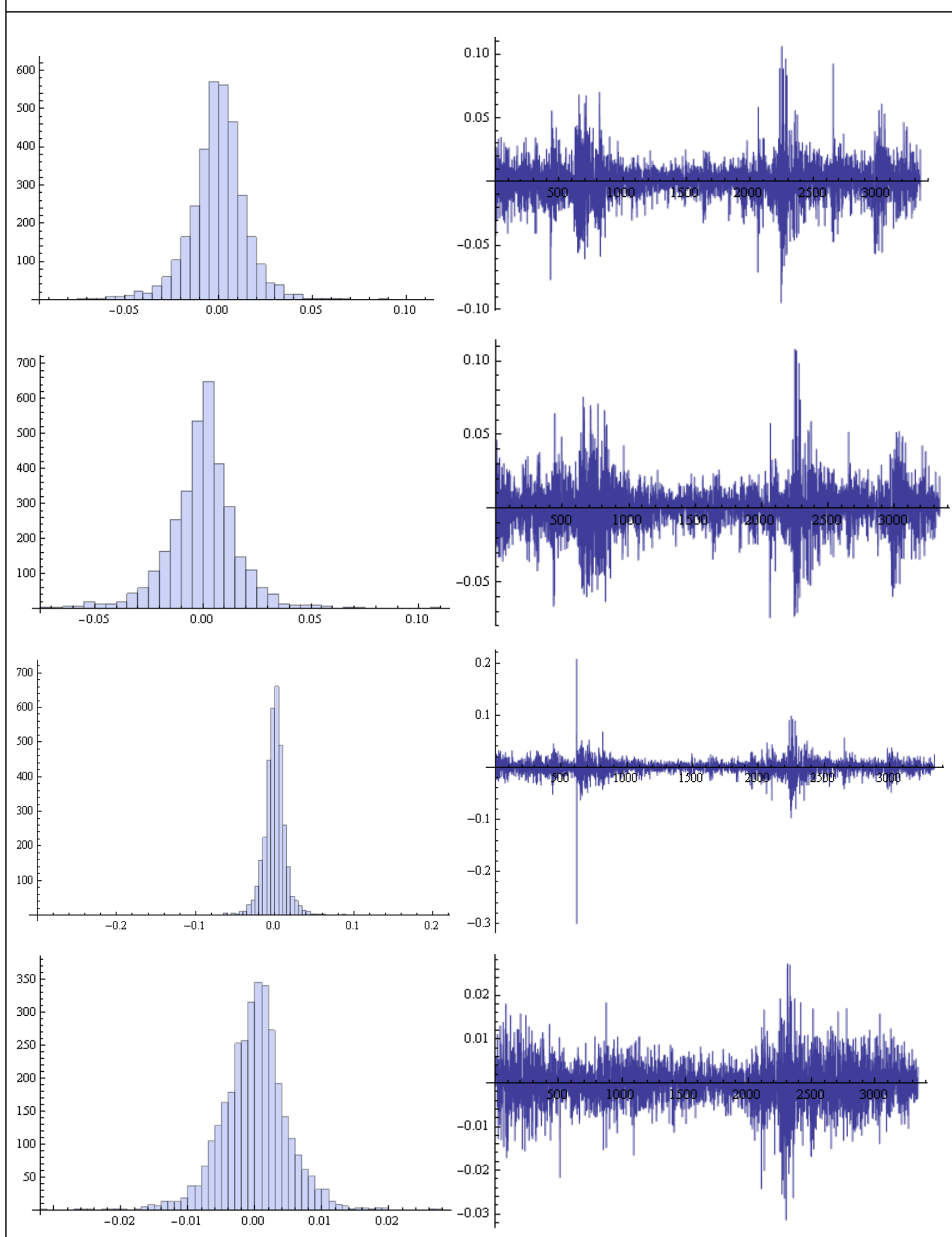

Source: Calculated by the authors with Wolfram Mathematica software using data from Bloomberg 
Therefore, EWMA is considered to be a good model to solve this problem. If the exponential coefficient is chosen as a big number, current variance effects will be small over total variance. EWMA model assumes that the weights for the last days are higher than for older days. JP Morgan used EWMA model for VaR calculation. EWMA responds to the volatility changes and EWMA does assume that volatility is not constant through time.

In finance, it is standard to use EWMA for squared daily returns and cross products of daily returns:

$$
\begin{aligned}
& \operatorname{VaR}(\alpha)_{t+1}=\sigma_{t+1} F^{-1}(\alpha), \\
& \sigma_{t+1}^{2}\left(r_{t}\right)=\lambda \sigma_{t}^{2}+(1-\lambda) r_{t}^{2}, \\
& \hat{\sigma}_{1}^{2}=\frac{1}{n} \sum_{t=1}^{n} r_{t}^{2} .
\end{aligned}
$$

This model puts geometrically declining weights on past observations, thus assigning greater importance to recent observations. Standard EWMA VaR in J.P. Morgan`s Risk Metrics method suggested to forecast the conditional volatility of short horizon asset returns in terms of conditional variance. This method is appropriate for financial assets, if the return series are really or approximately from a conditional Gaussian distribution (Nelson \& Foster, 1994). If the conditional distribution of the financial returns does not follow the Gaussian assumption, the standard EWMA estimator is inefficient in the sense that it will attach too much weight to extreme returns. When returns are leptokurtic, the standard EWMA estimator will be consistent, but it will be asymptotically inefficient, putting too much weight on observations which are either very large or very small and too little weight on those that are more moderate (Guermat \& Harris, 2001).

\section{Skewed EWMA based VaR modelling}

Skewed EWMA VaR model was developed by (Lu, Huang \& Gerlach, 2010). This estimator is based on asymmetric Laplace distribution to take into account both skewness and heavy tails in financial return distribution and it generalizes the robust EWMA VaR estimator as special case.

$$
\begin{aligned}
& \operatorname{VaR}_{t+1}=-\sigma_{t+1}\left[1+\left(\frac{1-p}{p}\right)^{2}\right]^{-\frac{1}{2}} \ln \frac{1-\alpha}{p} \\
& \sigma_{t+1}=(1-\lambda) \sum_{i=0}^{\infty} \lambda^{i}\left(\frac{k}{1-p} I_{\left[r_{t-i}>0\right]}+\frac{k}{p} I_{\left[r_{t-i}<0\right]}\right)\left|r_{t-i}\right|, \\
& \hat{\sigma}=\frac{1}{n} \sum_{i=1}^{n}\left(\frac{k}{p} I_{\left[r_{i}<0\right]}+\frac{k}{1-p} I_{\left[r_{i}>0\right]}\right)\left|r_{i}\right|
\end{aligned}
$$

where $k=k(p)=\sqrt{p^{2}+(1-p)^{2}}$ and $\lambda$ is a decaying factor.

Through iteration (7) can be expressed as

$$
\sigma_{t+1}=\lambda \sigma_{t}+(1-\lambda)\left(\frac{k}{1-p} I_{\left[r_{t}>0\right]}+\frac{k}{p} I_{\left[r_{t}<0\right]}\right)\left|r_{t}\right|
$$


If $p=0.5$, we obtain symmetric Laplace distribution and (6) and (9) reduce to

$$
\begin{aligned}
& V a R_{t+1}=-\frac{\sigma_{t+1}}{\sqrt{2}} \ln \{2(1-\alpha)\} \\
& \sigma_{t+1}=\lambda \sigma_{t}+(1-\lambda) \sqrt{2}\left|r_{t}\right|, 0<\lambda<1 \\
& \widehat{\sigma}=\frac{1}{n} \sum_{t=1}^{n} \sqrt{2}\left|r_{t}\right|
\end{aligned}
$$

which was proposed by (Guermat \& Harris, 2001).

If $p \neq 0.5$, then the contribution of the positive/negative value of $r_{t}$ to the $\sigma_{t+1}$ is quite different. The case $r_{t}>0$ means a good news and the cases $r_{t}<0$ means bad news. The volatility of this news is well characterized in (9). As it is written in (Lu, Huang \& Gerlach, 2010), this skewed-EWMA estimate of standard deviation (11) is a special first order threshold GARCH (TGARCH) model.

Parameter $p$ is a constant estimated by

$$
p=\frac{1}{1+\sqrt{\frac{u}{v}}},
$$

where

$$
u=\frac{1}{n} \sum_{i=1}^{n}\left|r_{i}\right| I_{\left[r_{i}>0\right]}, v=\frac{1}{n} \sum_{i=1}^{n}\left|r_{i}\right| I_{\left[r_{i}<0\right]}
$$

Obviously, $u$ is the averaged positive return and $v$ is the absolute value of averaged negative return. The larger $u$ is the better; but the larger $v$ is worse for investment.

\section{Results and Discussion}

In the empirical application for the data return series we found $95 \% \mathrm{VaR}$ for 10 days horizon and decaying factors $\lambda=0.97,0.98$ and 0.99 . Table 2 displays $\mathrm{VaR}$ that reflects the conditional distribution and the dynamic behaviour, such as time-varying volatility of a return series.

For a more volatile market the larger VaR should be obtained, otherwise a smaller VaR should be obtained. Figure 2 shows standard 95\% VaR and skewed 95\% VaR for 10 days horizon, both for $\lambda=0.98$. The blue line shows 10 days $95 \%$ VaR for FX exchange rate GBP/EUR, its volatility during the whole period was very low. The yellow line corresponds to FTSE index, red line and green line to CAC 40 and DAX index, respectively.

Volatility of the CAC 40 and DAX log returns was similar during the whole period, but compared to FX rate it was higher. Figure 2 clearly shows that the corresponding 10 days $95 \%$ VaR computed using skewed EWMA estimator gives lower forecast than standard EWMA estimator. 
Figure 2: $95 \% 10$ days Standard EWMA VaR and Skewed EWMA VaR $(\lambda=0.98)$ for the European stock indices CAC, DAX and FTSE and for exchange rates GBP/EUR from 3.1. 2000 to 2.1. 2013
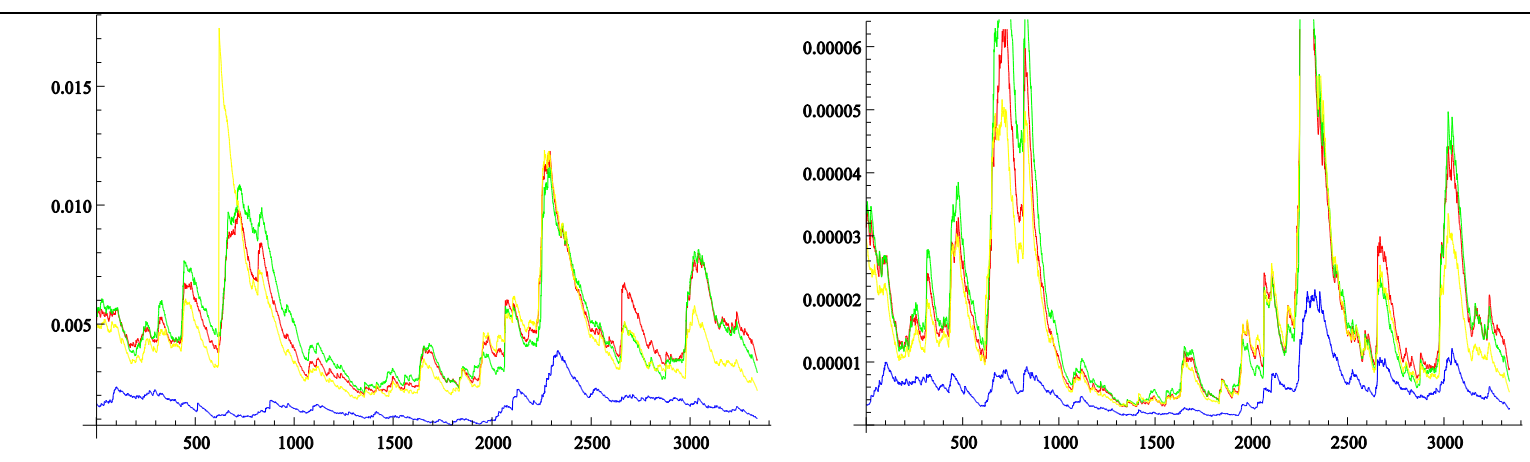

Source: Calculated by the authors with Wolfram Mathematica software using data from Bloomberg

Table 2: $95 \%$ VaR forecast for 10 days horizon

\begin{tabular}{|l|l|l|l|l|l|}
\hline \multicolumn{2}{|c|}{} & CAC & DAX & GBP/EUR & FTSE \\
\hline \multirow{2}{*}{\begin{tabular}{l}
$\lambda=0.97$ \\
$\alpha=0.05$ \\
\multirow{2}{*}{$\mathrm{T}=10$}
\end{tabular}} & Standard EWMA VaR & $0.307 \%$ & $0.253 \%$ & $0.095 \%$ & $0.195 \%$ \\
\cline { 2 - 6 } & Robust EWMA VaR. & $0.00969 \%$ & $0.00833 \%$ & $0.00113 \%$ & $0.00949 \%$ \\
\hline \multirow{2}{*}{$\begin{array}{l}\lambda=0.98 \\
\alpha=0.05 \\
\mathrm{~T}=10\end{array}$} & Skewed EWMA VaR & $0.00073 \%$ & $0.000526 \%$ & $0.000234 \%$ & $0.000412 \%$ \\
\cline { 2 - 6 } & Robust EWMA VaR. & $0.00647 \%$ & $0.00555 \%$ & $0.00075 \%$ & $0.00633 \%$ \\
\hline \multirow{2}{*}{$\begin{array}{l}\lambda=0.99 \\
\alpha=0.05\end{array}$} & Skewed EWMA VaR & $0.000898 \%$ & $0.000691 \%$ & $0.00027 \%$ & $0.000521 \%$ \\
\cline { 2 - 6 } & Robust EWMA VaR. & $0.00323 \%$ & $0.00277 \%$ & $0.00037 \%$ & $0.00316 \%$ \\
\cline { 2 - 6 } $\mathrm{T}=10$ & Skewed EWMA VaR & $0.001225 \%$ & $0.001059 \%$ & $0.000356 \%$ & $0.000765 \%$ \\
\hline
\end{tabular}

Source: Calculated by the authors with Wolfram Mathematica software using data from Bloomberg

\section{Conclusion}

EWMA estimator is widely used to forecast the variance of the conditional distribution of returns. However, the EWMA estimator is inefficient when the conditional distribution of returns is leptokurtic. In this paper, we suggest alternative skewed and robust EWMA estimator as a special case. We evaluate skewed EWMA, robust EWMA and standard EWMA 95\% VaR forecast for 10 day horizon, for $\lambda=0.97,0.98$ and 0.99 for three European market indexes and FX rate GBP/EUR. Our empirical investigation suggests that the skewed EWMA generate VaR forecasts that are more accurate as those based on the standard or robust EWMA estimator, in the sense that the average level capital required to hold against unexpected losses is lower. 


\section{Acknowledgment}

The work on this paper has been supported by VEGA grant agency, grant number 1/0279/11 .

\section{References}

Ahlawat, S. (2012). Calculating Value-at-Risk Using Option Implied Probability Distribution of Asset Price. Wilmott, 59, 56-61. http://dx.doi.org/10.1002/wilm.10113

Alexander, C. (2008). Market Risk Analysis. Chichester, England: John Wiley \& Sons.

Allen, S. (2003). Financial risk management. A practitioner`s Guide to Managing Market and Credit Risk. Hoboken, NJ: John Wiley \& Sons.

Allen, S., Boudoukh, J. \& Saunders, A. (2004). Understanding Market Credit and Operational Risk. Oxford, England: Blackwell Publishing.

Angelidis, T., Benos, A. \& Degiannakis, S. (2004). The use of GARCH models in VaR estimation. Statistical Methodology, 1 (12), 105-128. http://dx.doi.org/10.1016/j.stamet.2004.08.004

Basel Committee. (1996). Overview of the amendment to the capital accord to incorporate market risk. Basel, Switzerland: Basel committee on banking supervision.

Bohdalová, M. \& Greguš, M. (2012). Stochastické analýzy finančných trhov [Stochastic analysis of the financial markets]. Bratislava, Slovakia: Comenius University Press.

Culp, C., Mensink, R. \& Neves, M. P. (1999). Value at Risk for Asset Managers. Derivatives Quarterly, 5 (2).

De Schepper, A. \& Heijnent, B. (2010). How to estimate the Value at Risk under incomplete information. Journal of Computational and Applied Mathematics, 233, 2213-2226.

http://dx.doi.org/10.1016/j.cam.2009.10.007

Dempster, M. \& Howard, A. (2002). Risk Management Value at Risk and beyond. Cambridge, England: Cambridge University Press. http://dx.doi.org/10.1017/CBO9780511615337

Dowd, K. (2002). Measuring Market Risk. Chichester, England: John Wiley \& Sons.

Duffie, D. \& Pan, J. (1997). An overview of value at risk. Journal of Derivatives, 4 (3), 7-49. http://dx.doi.org/10.3905/jod.1997.407971

Fong, G. F. \& Vasicek, O. A. (1997): Portfolio Risk Management. Advanced in fixed income valuation modelling and risk management. (317-326). New Hope, PA: Frank J. Fabazzi Associates.

Guermat, C. \& Harris, R. D. F. (2001). Robust Conditional Variance Estimation and Value-at-Risk. Journal of Risk, 4, 25-41. Retrieved from: http://dx.doi.org/10.2139/ssrn.254569

Hubbert, S. (2012). Essential Mathematics for Market Risk Management. Chichester, England: John Wiley \& Sons. PMid:23097880

Jorion, P. (2007). Value at Risk. The New Benchmark for Managing Financial Risk. New York, NY: McGraw-Hill. PMid:17055638 
Jorion, P. (2009). Financial Risk Manager Handbook. Chichester, England: John Wiley \& Sons.

Korkmaz, T. \& Aydın, K. (2002). Using EWMA and GARCH methods in VaR calculations. Application on ISE-30 index ERC/METU 6. Paper presented at the International Conference in Economics, held in Ankara, Turkey, September 11-14, 2002. Retrieved March 10, 2013, from http://content.csbs.utah.edu/ ehrbar/erc2002/pdf/P161.pdf

Lin, L. (2008). Assessing the Performance of Value at Risk Models in Chinese Stock Market. (Doctoral dissertation). Available at University of Nottingham, Business School.

Linsmeier, T. J. \& Pearson, N. D. (1996). Risk Measurement. An Introduction to Value at Risk. (Working Paper). Chicago, IL: University of Illinois Press. http://dx.doi.org/10.2469/faj.v56.n2.2343

Linsmeier, T. J. \& Pearson, N. D. (2000). Value at Risk. Financial Analyst Journal, 3 (4).

Longerstaey, J. \& Spencer, M. (1996). Risk Metrics - Technical document. New York, NY: Morgan Guaranty Trust Company of New York.

Lu, Z., Huang, H. \& Gerlach, R. (2010). Estimating Value at Risk, From JP Morgan`s StandardEWMA to skewed-EWMA Forecasting OME. Working Paper No: 01/2010. Faculty of Economics and Business, The University of Sydney, Sydney, Australia.

McNeil, A. J., Frey, R. \& Embrechts, P. (2005). Quantitative Risk Management. Princeton, NJ: Princeton University Press.

Nelson, D. \& Foster, D. (1994). Asymptotic filtering theory for multivariate ARCH models. Econometrica, 62, 1-41. http://dx.doi.org/10.2307/2951474

Pearson, N. D. (2002). Risk budgeting. Portfolio Problem Solving with Value-at-Risk. New York, NY: John Wiley \& Sons.

Penza, P. \& Bansal, V. K. (2001). Measuring Market Risk with Value at Risk. New York, NY: John Wiley \& Sons.

Rossignolo, A. F., Fethi, M. D. \& Shaban, M. (2012). Value-at-Risk models and Basel capital charges. Evidence from Emerging and Frontier stock markets. Journal of Financial Stability, 8 (4), 303-319. http://dx.doi.org/10.1016/j.jfs.2011.11.003

Zmeškal, Z. (2005). Value at risk methodology of international index portfolio under soft conditions (fuzzy-stochastic approach). International Review of Financial Analysis, 14, 263-275.

http://dx.doi.org/10.1016/j.irfa.2004.06.011 